Check for updates

Cite this: RSC Adv., 2019, 9, 32759

Received 11th September 2019

DOI: $10.1039 / c 9 r a 07299 c$

rsc.li/rsc-advances Accepted 7th October 2019

\section{Retention of strong intramolecular hydrogen bonds in high polarity solvents in binaphthalene- benzamide derivatives: extensive NMR studies $\uparrow$}

\author{
Arun Kumar Patel, (iD $t^{a b}$ Sandeep Kumar Mishra, (iD $\$ \$^{b}$ Kiran Krishnamurthy (D) \\ and N. Suryaprakash (iD *ab
}

\begin{abstract}
Advanced multidimensional NMR techniques have been employed to investigate the intramolecular hydrogen bonds (HBs) in a series of $N, N^{\prime}$-([1, $1^{\prime}$-binaphthalene $]-2,2^{\prime}$-diyl)bis(benzamide) derivatives, with the site-specific substitution of different functional groups. The existence of intramolecular HBs and the elimination of any molecular aggregation and possible intermolecular HBs are ascertained by various experimental NMR techniques, including solvent polarity dependent modifications of HB strengths. In the fluorine substituted derivative, direct evidence for the engagement of organic fluorine in $\mathrm{HB}$ is obtained by the detection of heteronuclear through-space correlation and the coupling between two NMR active nuclei where the transmission of spin polarization is mediated through $\mathrm{HBs}\left({ }^{\mathrm{h}} \mathrm{J}_{\mathrm{FH}}\right)$. The extent of reduction in the strength of ${ }^{1 \mathrm{~h}} \mathrm{~J}_{\mathrm{FH}}$ on dilution with high polarity solvents directly provided the qualitative measure of HB strength. The HB, although becoming weakened, does not get nullified even in pure high polarity solvent, which is attributed to the structural constraints. The rate of exchange of a labile hydrogen atom with the deuterium of the solvent permitted the measurement of their half-lives, that are correlated to the relative strengths of HBs. The experimental NMR findings are further validated by XRD and DFT-based theoretical computations, such as, $\mathrm{NCl}$ and QTAIM.
\end{abstract}

\section{Introduction}

The HB, a weak molecular interaction plays a pivotal role in understanding many chemical and biological phenomena. ${ }^{\mathbf{1 - 4}}$ Numerous applications through inter- or intra-molecular interactions are found in supramolecular chemistry, biomolecules, such as, proteins, peptides, etc. ${ }^{5-7}$ The HB has thus been proven to be an important area of research, and is investigated by various analytical techniques $^{8}$ and many groups are constantly exploring the diverse utility of $\mathrm{HB}$ interactions. ${ }^{\mathbf{9}, 10}$ The commonly encountered HB motifs are of the type, $\mathrm{C}-\mathrm{H} \cdots \mathrm{O}, \mathrm{C}-\mathrm{H} \cdots \mathrm{N}$ and $\mathrm{N}-\mathrm{H} \cdots \pi, \mathrm{N}-\mathrm{H} \cdots \mathrm{O}, \mathrm{O}-\mathrm{H} \cdots \mathrm{O}$, and $\mathrm{O}-\mathrm{H} \cdots \mathrm{N}$. These $\mathrm{HB}$ interactions could be both intra- and inter and have significant contributions in determining the structures and conformations of the molecules. ${ }^{11}$ The strength of intramolecular HBs also can control the population of different conformers for a molecule. ${ }^{12}$

${ }^{a}$ Solid State and Structural Chemistry Unit and NMR Research Centre, Indian Institute of Science, Bangalore 560012, India.E-mail: suryaprakash1703@gmail.com; nsp@ iisc.ac.in; Fax: +91-80-23601550; Tel: +91-80-22933300; +91-8023607344; $+919845124802$

${ }^{b}$ NMR Research Centre, Indian Institute of Science, Bangalore 560012, India

$\dagger$ Electronic supplementary information (ESI) available. See DOI: 10.1039/c9ra07299c

\$ These authors contributed equally.

$\S$ Present address: Department of Physics, Indian Institute of Science Education and Research, Dr Homi Bhabha Road, Pashan, Pune 411008, India.
The fluorine is one of the essential atoms presents in majority of the drugs due to its bio-availability and stability. On an average nearly $30 \%$ of commercial drugs contain at least one fluorine atom to enhance the metabolic stability, binding affinity and to alter physicochemical properties. ${ }^{13}$ To highlight the importance of fluorine containing drugs, the three out of the top 10 best-selling drugs, Lipitor, Advair and Crestor contain a fluorine atom, and seven out of 35 approved drugs in 2011 contain a fluorine atom. ${ }^{\mathbf{1 4}}$ The dynamics and the interaction of these drug molecules with the biomolecules are controlled by HB. Dunitz et al. have reported that organic fluorine hardly ever accepts hydrogen bond. ${ }^{15}$ Nevertheless over the years the involvement of organic fluorine in $\mathrm{HB}$ in large number of molecules including foldamers have been reported. ${ }^{16-22}$ The studies report that the inter- or intra-molecular $\mathrm{HB}$ of the type $\mathrm{X}-\mathrm{H} \cdots \mathrm{F}-\mathrm{C}(\mathrm{X}=\mathrm{O}, \mathrm{N})$ plays a significant role in the dynamics as well as the functionalities of the drugs ${ }^{23}$ viz., dipole-dipole interaction, HB and steric hinderance.

In the present work, various 1,1'-binaphthalene-2,2'-diamine (BINAM) derivatives have been synthesized and characterised using several one and two-dimensional multi-nuclear NMR techniques as well as, XRD and ESI-HR mass spectrometry. The procedure for synthesis of all the investigated molecules and their NMR spectra along with the assignment of peaks are reported in ESI. $\dagger$ The structural frameworks of the molecules investigated are given in Scheme 1. The utility of BINAM and its 
derivatives is multifold, viz., synthesis of [BINAM-FeCl 2 ] complex for the conversion of indole into bisindolylmethane with high yield,$^{24}$ to derivatize an organocatalyst for the asymmetric synthesis in Henry reaction which yields the high reactivity and enantioselectivity, ${ }^{25}$ the covalently linked azobenzene and the enantiopure BINAM is able to produce materials that exhibits photoresponsive chiroptical behaviour due to cis-trans isomerism shown by its backbone. ${ }^{26}$ In many chemical reactions, the proton transfer due to the complex formation through HB is also reported. ${ }^{27}$ The transfer of hydrogen atom occurs during the rate determining step. The lability of this hydrogen depends on its chemical environment and the strength of HB. It has been previously reported that the rate of $H / D$ exchange depends on both the strength of HB as well as electronic effects of the substituents. ${ }^{28,29}$ When the deuterated solvent is present in excess, this exchange phenomenon is known to follow the pseudo first order kinetics. This concept has been exploited in the present study for monitoring the rate of exchange of labile hydrogen atom with the deuterium of the solvent to extract information on the relative strengths of HB. The proton transfer due to the complex formation through hydrogen bonding is also reported. In this investigation we have convincingly established the presence of very strong $\mathrm{HB}$ in the number of synthesize derivatives of BINAM. This could aid in the architectural design and understanding of the role of BINAM in many other chemical and photochemical reactions.

\section{Results and discussion}

Initially the fluorinated derivative (molecule 1 in Scheme 1) was chosen for in-depth analysis. The spatial proximity being the fundamental requirement for any two nuclei to get involved in $\mathrm{HB}$, the 2D ${ }^{1} \mathrm{H}-{ }^{19} \mathrm{~F}$ HOESY (Hetero- $n$ OE Spectroscopy) ${ }^{30-32}$ experiment was carried out and the corresponding spectrum is reported in Fig. 1. The strong through space correlation detected between ${ }^{19} \mathrm{~F}$ and the $\mathrm{NH}$ proton established their close spatial proximity conducive for the HB interaction.

\section{NMR detection of $\mathrm{HB}$}

Number of NMR parameters are available for understanding the presence of $\mathrm{HB}$ in a molecule. In the solution state, the chemical

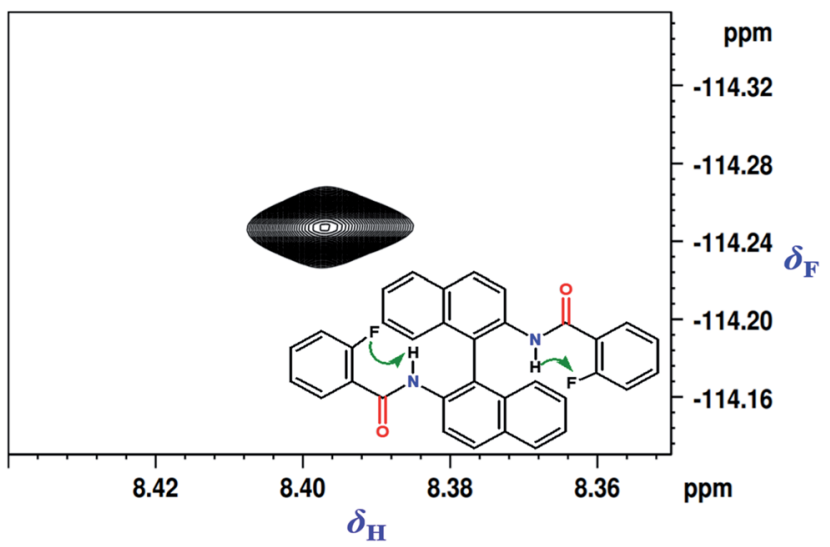

Fig. $12 \mathrm{D}^{1} \mathrm{H}-{ }^{19} \mathrm{~F}$ HOESY spectrum of molecule 1 in the solvent $\mathrm{CDCl}_{3}$. The chemical structure of the molecule is also given in the inset and the through space correlated spins are identified by arrows.

shift of the protons involved in HB is usually monitored, which is known to move downfield compared to non-hydrogen bonded proton owing to the depletion of electronic charge distribution around it. The chemical shift of $\mathrm{NH}$ proton of the unsubstituted molecule is $7.76 \mathrm{ppm}$, while those of the substituted molecules are between 7.95 to 9.67 ppm with $\mathrm{OCH}_{3}$ substituted molecule shifted to extreme downfield ( $9.67 \mathrm{ppm})$ confirming the presence of $\mathrm{HB}$ in all these molecules.

The energy of HB can be calculated by using experimentally measured chemical shifts employing the relation $E_{\mathrm{HB}}$ (kcal $\left.\mathrm{mol}^{-1}\right)=\Delta \delta+(0.4 \pm 0.2)$, where $\Delta \delta$ pertains to the difference in the chemical shift of proton between the substituted and unsubstituted molecules. ${ }^{12,33}$ The calculated $E_{\mathrm{HB}}$ for the molecules 1-3 are compiled in Table 1.

\section{Distinguishing between intra- and inter-molecular $\mathrm{HB}$}

To ascertain whether HB is intra- or inter-molecular, generally the solvent dilution experiments are employed. ${ }^{34-37}$ This experiment also provides information on the effect of monomeric water absorbed by the solvent from the atmosphere. ${ }^{36,37}$ The changes in the chemical shift of $\mathrm{NH}$ proton as a function of the concentration of $\mathrm{CDCl}_{3}$, in the molecules 1-4, is graphically illustrated in Fig. 2A. The chemical shift of $\mathrm{NH}$ proton remained

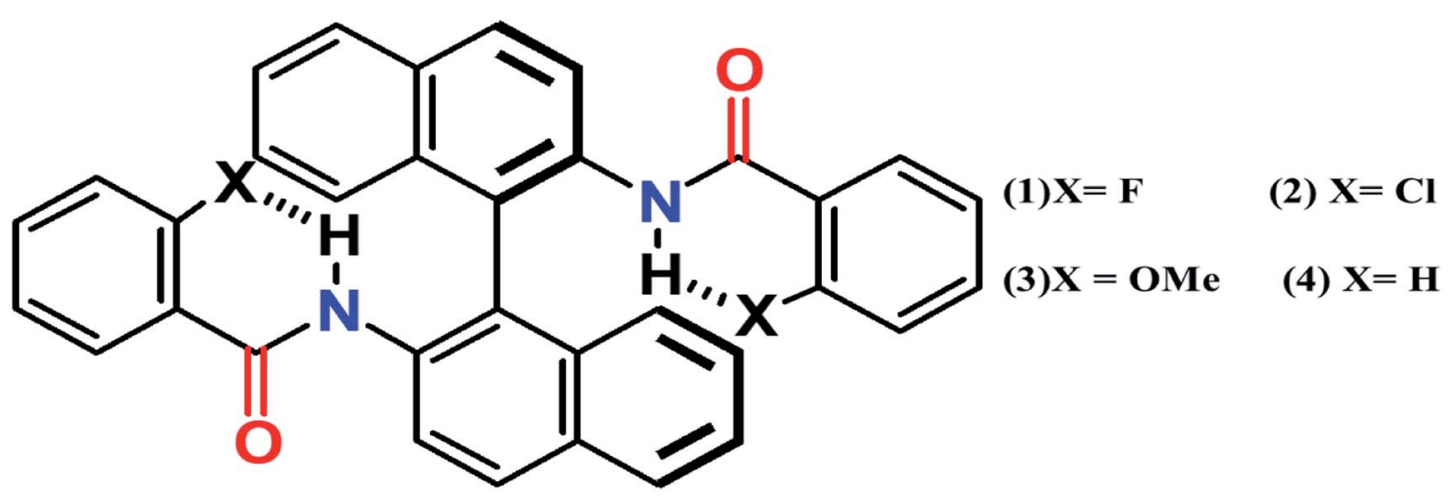

Scheme 1 The structural framework of $(R)-(+)-N, N^{\prime}-\left(\left[1,1^{\prime}\right.\right.$ - binaphthalene]-2,2'-diyl)bis(benzamide) and its derivatives. 
Table 1 Calculated $E_{\mathrm{HB}}$ employing the difference in chemical shift values of the substituted molecules 1-3 with respect to that of unsubstituted molecule 4

\begin{tabular}{lllll}
\hline Molecule & $\begin{array}{l}\text { Substituent } \\
(\mathrm{X})\end{array}$ & $\begin{array}{l}\delta_{\mathrm{NH}} \\
\text { in the solvent } \mathrm{CDCl}_{3}(\mathrm{ppm})\end{array}$ & $\begin{array}{l}\text { Difference in } \delta_{\mathrm{NH}} \\
\text { with respect to molecule } \mathbf{4}\end{array}$ & $\begin{array}{l}\text { Energy of HB }\left(E_{\mathrm{HB}}\right)(\mathrm{kcal} \\
\left.\mathrm{mol}^{-1}\right)\end{array}$ \\
\hline $\mathbf{1}$ & $\mathrm{F}$ & 8.34 & 0.59 & 0.99 \\
$\mathbf{2}$ & $\mathrm{Cl}$ & 7.97 & 0.22 & 0.62 \\
$\mathbf{3}$ & OMe & 9.67 & 1.92 & 2.32 \\
$\mathbf{H}$ & $\mathrm{H}$ & 7.75 & - & -
\end{tabular}

nearly same on dilution, within the experimental error, establishing the absence of intermolecular $\mathrm{HB}$, as well as any possible aggregation and dimerization in all the molecules. This also convincingly establishes the presence of intramolecular HB. The chemical shift of water in $\mathrm{CDCl}_{3}$ at $1.54 \mathrm{ppm}$ remained unchanged, except for marginal change during dilution, further discarding any effect of atmospheric water on the molecular interactions. The subsequent step is to determine the relative strengths of these intramolecular HBs, which is determined by the ease at which they can be ruptured in a high polarity solvent, such as, DMSO. ${ }^{38}$ The strong interaction between DMSO and the $\mathrm{NH}$ proton results in the disruption of intramolecular HBs causing a downfield shift of $\mathrm{NH}$ proton chemical shift. ${ }^{38,39}$ The quantity of DMSO required to rupture a HB is directly proportional to its strength. The changes in the chemical shift of $\mathrm{NH}$ proton with the incremental addition of DMSO- $\mathrm{d}_{6}$ to the initial $10 \mathrm{mM}$ solution in $\mathrm{CDCl}_{3}$ is reported in Fig. 2B, for all the molecules. As expected, in the molecules 2 and 4 there is substantial down field shift in the resonance position of $\mathrm{NH}$ proton. On the contrary in molecule 3 the $\mathrm{NH}$ proton shifted to high field, which is attributed to the comparatively stronger HB between oxygen atom of the methoxy group and $\mathrm{NH}$ proton compared to its interaction with DMSO in the two competitive processes. ${ }^{40}$

Another physical parameter that provides information on the $\mathrm{HB}$ is the temperature. The lowering of the temperature enhances the strength of $\mathrm{HB}$ and results in the downfield shift of the proton involved in $\mathrm{HB}^{\mathbf{4 1 , 4 2}}$ When the temperature is varied from $220 \mathrm{~K}$ to $300 \mathrm{~K}$ the $\mathrm{NH}$ proton of molecules 1-4 exhibited the downfield shift, which is evident from Fig. 3. From the magnitude of change in the value of $\delta_{\mathrm{NH}}$, one can conclude that the relative $\mathrm{HB}$ strengths follow the trend, $\mathrm{OMe}>\mathrm{F}>\mathrm{Cl}>\mathrm{H}$.

\section{HB mediated coupling between NMR active nuclei}

When ${ }^{19} \mathrm{~F}$ is involved in $\mathrm{HB}$, often the coupling between ${ }^{1} \mathrm{H}$ and ${ }^{19} \mathrm{~F}$ mediated through $\mathrm{HB}$ is detected, giving a strong evidence on the existence of $\mathrm{HB}^{33,43}$

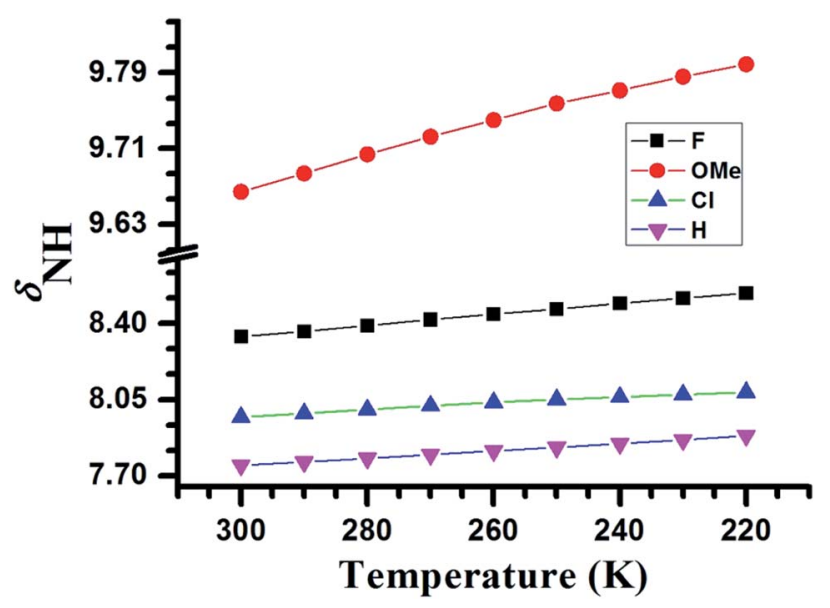

Fig. 3 Variation in the chemical shifts of $\mathrm{NH}$ proton $\left(\delta_{\mathrm{NH}}\right)$ as a function of temperature in the range of $300 \mathrm{~K}$ to $220 \mathrm{~K}$ for the molecules $1-4$. The molecules are identified by the symbols given in the inset.
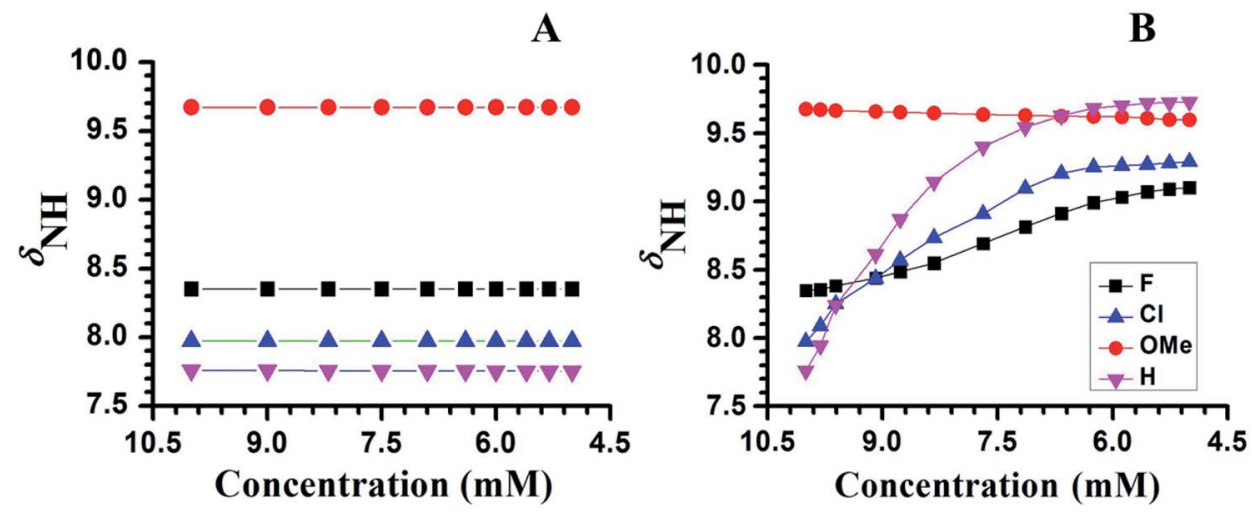

Fig. 2 Chemical shifts of $\mathrm{NH}$ proton $\left(\delta_{\mathrm{NH}}\right)$ of molecules $1-4$, as a function of concentration in $\mathrm{CDCl}_{3}$ and DMSO- $\mathrm{d}_{6}$ respectively. The initial concentration taken was $10 \mathrm{mM}$ in the solvent $\mathrm{CDCl}_{3}$ and the temperature was maintained at $298 \mathrm{~K}$. (A) With the incremental addition of $\mathrm{CDCl}_{3}$ to an initial volume of $450 \mu \mathrm{L}$. (B) With the incremental addition of DMSO- $\mathrm{d}_{6}$ to an initial volume of $450 \mu \mathrm{L}$ in $\mathrm{CDCl}_{3}$. The molecules are identified by the symbols given in the inset of (B). 
The substantially large values of ${ }^{3} J_{\mathrm{FH}}$ about $4-5 \mathrm{~Hz}$, between ortho fluorine and $\mathrm{OH}$ proton, have been measured in the derivatives of 2-fluoro phenol ${ }^{44}$ which is not uncommon. In general, the observed ${ }^{n} J_{\mathrm{FH}}$ values are in the range of $40-60 \mathrm{~Hz}$, 2-15 Hz, 1-5 Hz, for $n=1,2$ and 3 respectively. The ${ }^{5} J_{\mathrm{FH}}$ is usually very small and less than $0.5 \mathrm{~Hz}$. On the other hand, the observation of coupling of $14-18 \mathrm{~Hz}$ between ${ }^{19} \mathrm{~F}$ and ${ }^{1} \mathrm{H}$ separated by five chemical bonds is unusual and is attributed to the HB mediated coupling.

The ${ }^{1} \mathrm{H}$ and ${ }^{1} \mathrm{H}\left\{{ }^{19} \mathrm{~F}\right\}$ spectra of molecule 1 in the solvent $\mathrm{CDCl}_{3}$ and DMSO- $\mathrm{d}_{6}$ are reported in Fig. 4. The NH proton is a doublet with a separation of $16.3 \mathrm{~Hz}$. The reported values of $\left({ }^{5} J_{\mathrm{FH}}\right)$ is usually less than $1 \mathrm{~Hz}$ and this large value of coupling is attributed to the one bond $\mathrm{HB}$ mediated coupling between ${ }^{1} \mathrm{H}$ and ${ }^{19} \mathrm{~F}\left({ }^{1 \mathrm{~h}} \mathrm{~J}_{\mathrm{FH}}\right)$. This is due to the interaction between $\mathrm{NH}$ proton and fluorine atom, which is also validated by collapsing of the doublet to a singlet in the ${ }^{1} \mathrm{H}\left\{{ }^{19} \mathrm{~F}\right\}$ spectrum. Previous studies have shown that such coupling gets completely nullified in a high polarity solvent, such as, DMSO giving another strong evidence for weak interaction. ${ }^{45}$ Interestingly in the present study the $\mathrm{NH}$ proton continues to remain as a doublet even in the solvent DMSO- $\mathrm{d}_{6}$, although coupling strength is substantially reduced. This indicates that the HB interaction in this molecule is significantly stronger and does not get ruptured even in the highly polar solvent medium compared to the previously reported studies. ${ }^{\mathbf{4 5 , 4 6}}$

The $2 \mathrm{D}{ }^{1} \mathrm{H}$ coupled and decoupled ${ }^{1} \mathrm{H}-{ }^{15} \mathrm{~N}$ HSQC spectra, where the ${ }^{15} \mathrm{~N}$ is in its natural abundance, provide strong evidence on the presence of intramolecular HBs and also helps in the precise determination of the relative signs and magnitudes of couplings. ${ }^{\mathbf{4 6 , 4 7}}$ The corresponding spectra are reported in Fig. 5. The coupled and decoupled ${ }^{1} \mathrm{H}^{-15} \mathrm{~N}$ HSQC spectra in the solvent $\mathrm{CDCl}_{3}$ are reported in Fig. 5A and $\mathrm{B}$, respectively. In Fig. 5A the couplings ${ }^{1} J_{\mathrm{NH}},{ }^{1 \mathrm{~h}} J_{\mathrm{FH}}$ and ${ }^{2 \mathrm{~h}} J_{\mathrm{FN}}$ persist while in Fig. $5 \mathrm{~B}$ the ${ }^{1} J_{\mathrm{NH}}$ has completely disappeared. The coupled ${ }^{1} \mathrm{H}-{ }^{15} \mathrm{~N}$ HSQC spectrum in the solvent DMSO- $\mathrm{d}_{6}$ (Fig. 5C), revealed all the couplings that were observed in $\mathrm{CDCl}_{3}$ (Fig. 5A). However, there is a significant change in the magnitudes of the couplings. The ${ }^{1} J_{\mathrm{NH}}$ increased by nearly $3 \mathrm{~Hz}$, whereas ${ }^{1 \mathrm{~h}} J_{\mathrm{FH}}$ and ${ }^{2 \mathrm{~h}} J_{\mathrm{FN}}$ decreased significantly in their strengths. The ${ }^{1} \mathrm{H}^{15}{ }^{15} \mathrm{HSQC}$ spectra of all the remaining molecules are reported in the ESI. $\dagger$ Taking advantage of the previous reports, the relative signs of ${ }^{1 \mathrm{~h}} J_{\mathrm{FH}}$ and ${ }^{2 \mathrm{~h}} J_{\mathrm{FN}}$ are assigned to be negative. ${ }^{33,39}$ The measured magnitudes and relative signs of all the couplings are reported in the figure.

\section{Nature of $\mathbf{H B}$}

For covalent and electrostatic HB, there will be a noticeable difference in the angle formed among the hydrogen bonding nuclei. In the directional covalent type $\mathrm{HB}$, the bond angle tends to be linear. On the other hand, in electrostatic nature of $\mathrm{HB}$ the bond angle is less leading to non-directional coulombic interaction. In electrostatic nature of $\mathrm{HB}$, due to the Fermi-contact mechanism the ${ }^{1} J_{\mathrm{NH}}$ increases with the shortening of $\mathrm{N}-\mathrm{H}$ bond length. On the other hand, in covalent type HB due to both Fermi-contact and paramagnetic spin-orbital mechanisms the ${ }^{1} J_{\mathrm{NH}}$ decreases with the lengthening of $\mathrm{N}-\mathrm{H}$ bond. ${ }^{46}$ The scalar coupling constant ${ }^{1} J_{\mathrm{NH}}$ is also utilized for understanding the nature of HBs. If the $\mathrm{HB}$ is predominantly electrostatic ${ }^{46}$ the strength of ${ }^{1} J_{\mathrm{NH}}$ increases when compared to unsubstituted
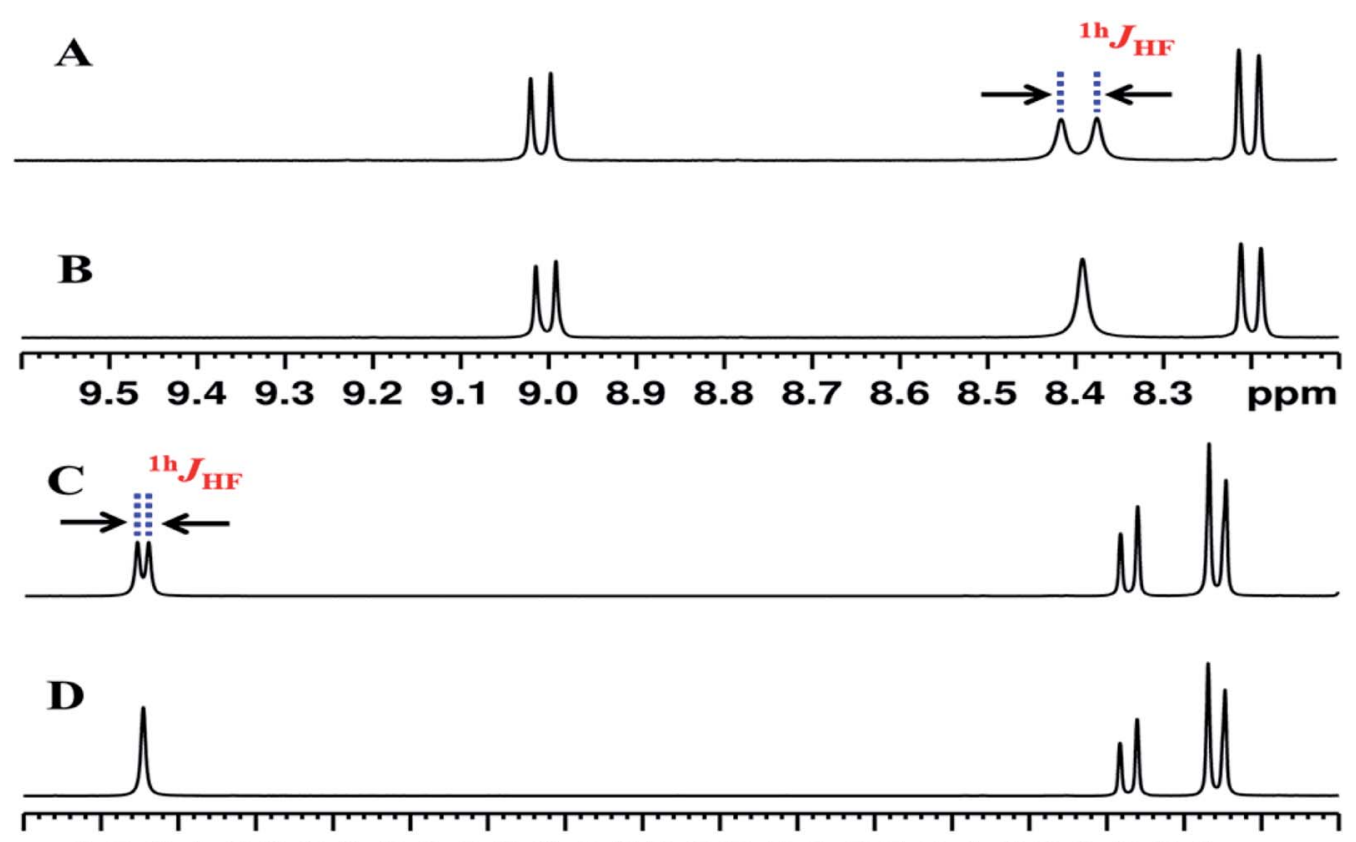

9.5 9.4 9.3 9.2 9.1 9.0 8.9 8.8 8.7 8.6 8.5 8.4 8.3 8.2 8.1 ppm

Fig. 4 Selected regions of the $400 \mathrm{MHz}^{1} \mathrm{H}$ NMR spectra of molecule 1 : (A) in the solvent $\mathrm{CDCl}_{3} ;(\mathrm{B}){ }^{1} \mathrm{H}\left\{{ }^{19} \mathrm{~F}\right\}$ spectrum in the solvent $\mathrm{CDCl}$; $(\mathrm{C})$ in the solvent DMSO- $d_{6}$; and (D) ${ }^{1} \mathrm{H}\left\{{ }^{19} \mathrm{~F}\right\}$ spectrum in the solvent DMSO-d $\mathrm{d}_{6}$. The doublet separation pertaining to ${ }^{1 \mathrm{~h}} \mathrm{~J}_{\mathrm{FH}}$ in $\mathrm{A}$ and $\mathrm{C}$ are identified. It may be noted that upon addition of DMSO- $d_{6}$ the $\mathrm{NH}$ peak shifted downfield and the magnitude of ${ }^{1 \mathrm{~h}} \mathrm{~J}_{\mathrm{FH}}$ is also reduced. The peaks at $9.0 \mathrm{ppm}$ and $8.2 \mathrm{ppm}$ in $\mathrm{CDCl}_{3}$, have moved high field to 8.17 and 8.06 respectively in $\mathrm{DMSO}-\mathrm{d}_{6}$ due to rupturing of $\mathrm{C}=\mathrm{O} \cdots \mathrm{H}$ (ring) $\mathrm{HB}$. 


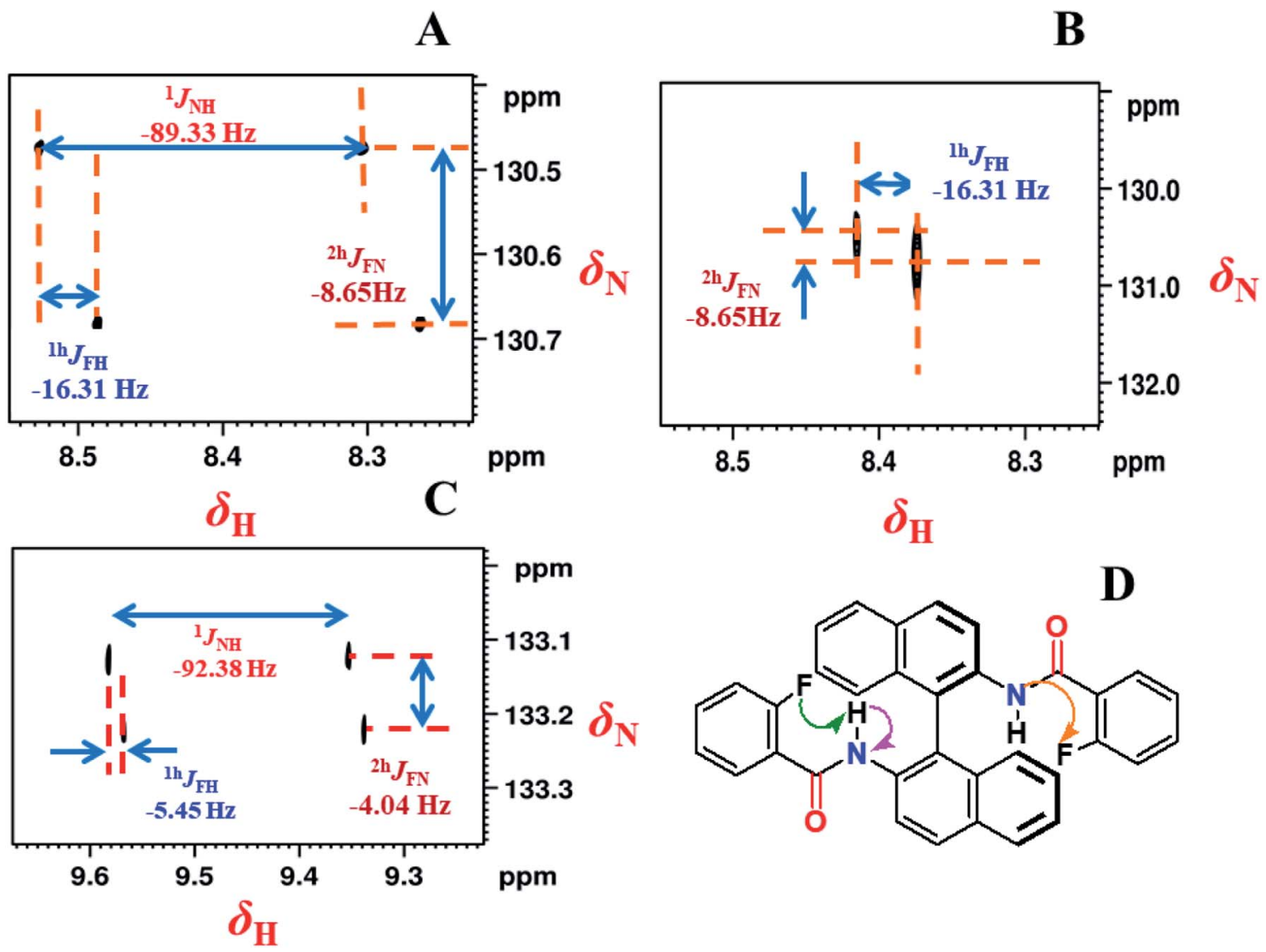

Fig. $5800 \mathrm{MHz}{ }^{1} \mathrm{H}-{ }^{15} \mathrm{~N}$-HSQC spectra of molecule 1 in the solvent $\mathrm{CDCl}_{3}$; (A) $\mathrm{NH}$-coupled; (B) $\mathrm{NH}$-decoupled; (C) $400 \mathrm{MHz}{ }^{1} \mathrm{H}-{ }^{15} \mathrm{~N}$ - $\mathrm{HSQC}$ spectrum ( $\mathrm{NH}$-coupled) in the solvent DMSO- $\mathrm{d}_{6} ;(\mathrm{D})$ the chemical structure of the molecule. The scalar and HB mediated couplings are identified by arrows in the chemical structure. The separations providing the scalar and HB mediated couplings and the measured values along with their relative signs derived from the slopes of the displacement of cross sections are mentioned in the spectra.

molecule, whereas it decreases for covalent type. ${ }^{47}$ From the ${ }^{1} J_{\mathrm{NH}}$ values given in Table 5 , it is evident that the HBs are predominantly of covalent type.

\section{Strong and unbreakable HB in highly polar solvent}

In the number of previous studies reported from our group, the ${ }^{1 \mathrm{~h}} \mathrm{~J}_{\mathrm{FH}}$ disappeared in a high polarity solvent DMSO- $\mathrm{d}_{6} \cdot{ }^{16,29}$ Interestingly in the present study the strength of $\mathrm{N}-\mathrm{H} \cdots \mathrm{F}-\mathrm{C}$ HB is so strong that it gets weakened but does not get completely ruptured even in pure solvent DMSO- $\mathrm{d}_{6}$. Such an unusual behaviour has been reported earlier in monosaccharides, inositols and ginkgolides ${ }^{48}$ where the strength of HB has been correlated to the value of ${ }^{1 \mathrm{~h}} \mathrm{~J}_{\mathrm{HF}}$. In fluorinated myo-inositol ${ }^{1 \mathrm{~h}} \mathrm{~J}_{\mathrm{HF}}$ reduced from $8.8 \mathrm{~Hz}$ in $\mathrm{CDCl}_{3}$ to $3.8 \mathrm{~Hz}$ in DMSO- $\mathrm{d}_{6}$. The coupling constant did not reduce beyond this value, and it was interpreted due to molecular constraints and the solvation of the $\mathrm{F} \cdots \mathrm{H}-\mathrm{O}$ bond was not completely favourable by DMSO- $\mathrm{d}_{6}$. Similar observation is made in the present study, where upon increasing the concentration of DMSO- $\mathrm{d}_{6}$ there is a smooth reduction in ${ }^{1 \mathrm{~h}} \mathrm{~J}_{\mathrm{FH}}$ consequent to weakening of $\mathrm{HB}$ and beyond a particular concentration the coupling strength remained unaltered even with excessive addition of DMSO- $\mathrm{d}_{6}$. This is graphically illustrated in Fig. 6. These observations evidently establish the presence of a very strong $\mathrm{HB}$. This was also observed in the $2 \mathrm{D}^{15} \mathrm{~N}-{ }^{1} \mathrm{H}$ HSQC spectrum (Fig. $5 \mathrm{C}$ ) where ${ }^{1 \mathrm{~h}} J_{\mathrm{HF}}$ is retained in pure DMSO- $\mathrm{d}_{6}$ solvent with a reduced value compared to that in $\mathrm{CDCl}_{3}$.

\section{Solvent polarities and strengths of $\mathrm{HB}$}

The ${ }^{1 \mathrm{~h}} J_{\mathrm{FH}}$ was also measured in solvents of different polarities and are assimilated in Table 2. From the table it is evident that with the increase in the solvent polarity there is a substantial decrease in the coupling constant. Although the decrease is not monotonic, the change is drastic in the solvents of high polarity. This is attributed to the structural constraint. The XRD structure of this molecule (Fig. 8, discussed in the later part of the article) revealed the constrained structure for binaphthyl derivative, and the $\mathrm{HB}$ between $\mathrm{F} \cdots \mathrm{HN}$ is facing towards one of the naphthyl rings. Thus, the complete solvation of this hydrogen bond is restricted by this constrained structure, thereby preventing the complete nullification of ${ }^{1 \mathrm{~h}} J_{\mathrm{FH}}$ (Table 2).

\section{H/D exchange}

The H/D exchange studies were carried out for all the samples to determine the exchange rate constants and the half-lives, which were subsequently utilized to determine the relative strengths 


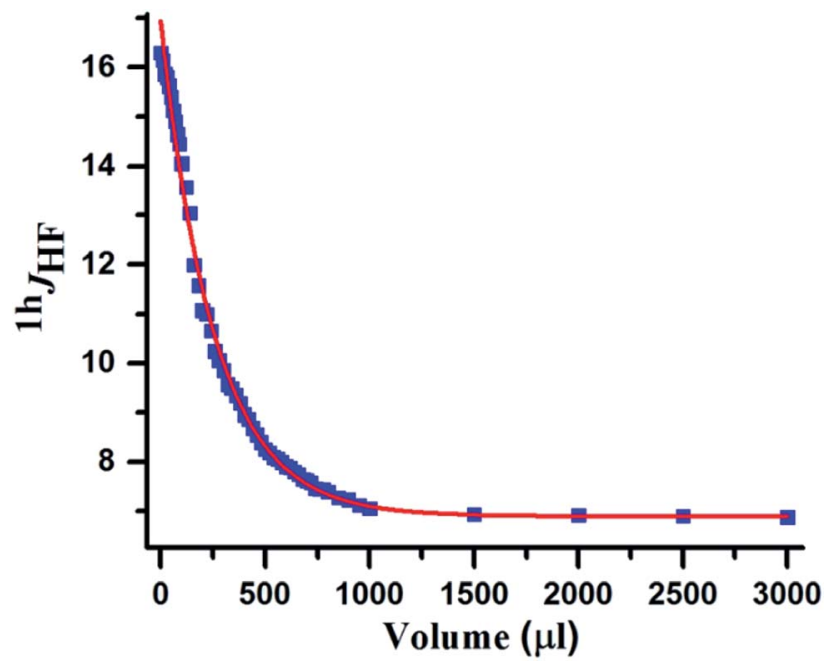

Fig. 6 The plot of $\mathrm{HB}$ mediated coupling $\left({ }^{1 \mathrm{~h}} \mathrm{~J}_{\mathrm{HF}}(\mathrm{Hz})\right)$ vs. volume of DMSO- $d_{6}(\mu \mathrm{L})$ for molecule 1.

of HBs. For such a purpose usually OD group of the $\mathrm{D}_{2} \mathrm{O}$ is used. Since in the present organic molecules the solubility in water is an issue, the deuterated solvent $\mathrm{CD}_{3} \mathrm{OD}$ was added to the solution of each sample. The series of ${ }^{1} \mathrm{H}$ NMR spectra were then obtained at the concentration of about $5 \mathrm{mM}$, with $450 \mu \mathrm{L}$ of $\mathrm{CDCl}_{3}$ solvent, at two minutes intervals till the intensity of $\mathrm{NH}$ proton drops to nearly zero. At this concentration the possibility for any kind of aggregation and intermolecular interaction are negligible. To minimize the effect of atmospheric water on $\mathrm{H} / \mathrm{D}$ exchange, the fresh ampules of $\mathrm{CD}_{3} \mathrm{OD}$ and $\mathrm{CDCl}_{3}$ were used. The final methanol concentration was kept at nearly $2.47 \mathrm{M}$, in $10 \%$ methanol : chloroform solution, in order to ensure that the exchange phenomenon follows pseudo-first order kinetics. A constant baseline correction was applied with the line broadening window function of $1 \mathrm{~Hz}$. The intensities of $\mathrm{NH}$ peaks were measured relative to the integral intensity of a non-exchanging and distinct signal of aromatic proton. The integral intensity of the $\mathrm{NH}$ peak was normalized to 1 at zero time and the intensities of the peak at different times were calibrated relative to this intensity. The change in the integral intensity of $\mathrm{NH}$ peak as a function of time is graphically represented in Fig. 7. From the graph, the slope of a nonlinear least squares fit on the first order kinetics equation $A(t)=A(0)$ $\exp (-k t)$, the rate constants and their corresponding half-lives

Table 2 Measured magnitudes of ${ }^{1} \mathrm{~J}_{\mathrm{HF}}$ for molecule 1 in solvents of different polarities. The polarity increases on going from top to bottom of the table

\begin{tabular}{lc}
\hline Solvent & ${ }^{1 \mathrm{~h}} J_{\mathrm{HF}}(\mathrm{Hz})$ \\
\hline Toluene-d & \\
Benzene- $\mathrm{d}_{6}\left(\mathrm{C}_{7} \mathrm{D}_{6}\right)$ & 17.45 \\
Chloroform $_{6}\left(\mathrm{CDCl}_{3}\right)$ & 17.39 \\
Pyridine-d $_{5}$ & 16.34 \\
DMSO-d $_{6}$ & 8.99 \\
& 5.45
\end{tabular}

were measured. The similar procedure was adopted for all the molecules 1-4 (Table 3).

From the measured rate constants and the half-lives, it is observed that the relative strengths of $\mathrm{HB}$ in the molecules follow the order; OMe $>\mathrm{F}>\mathrm{Cl}>\mathrm{H}$. This is also in agreement with the temperature dependent change in chemical shift of $\mathrm{NH}$ proton discussed in the earlier part of the manuscript.

\section{Single crystal X-ray diffraction (XRD) analysis}

One of the criteria set by IUPAC ${ }^{49}$ for the existence of $\mathrm{HB}$ in a molecule is the linearity of the $\left(180^{\circ}\right) \mathrm{Y}-\mathrm{H} \cdots \mathrm{X}$ bond angle. The bond angle closer to this value causes shortening of the $\mathrm{H} \cdots \mathrm{X}$ distance which ensures stronger HB. For measuring the bond angles and bond lengths, the single crystal XRD structure was obtained for the molecule $\mathbf{1}$ and is given in Fig. 8. The bond angle and bond lengths obtained from XRD data are given in Table 4 and compared with those obtained from DFT based computations. The detailed discussion on the DFT calculations is provided in the later part of the article. The structural parameters derived from DFT are also reported in Table 4 . The bond angles and bond lengths thus derived agree with the criteria for the existence of $\mathrm{HB}$ in the molecule.

\section{Theoretical studies}

The information obtained from NMR experiments was further confirmed by DFT based theoretical computations. All the molecular structures were optimised by Gaussian 09 suite, ${ }^{50}$ with a B3LYP/6-311+G(d,p) level of theory and default chloroform for solvation where integral equation formalism model (IEFPCM) is the solvent model. The lowest energy molecular structures were justified based on the positive harmonic vibrational frequency values. From the coordination of the minimum energy structures, the wave function files were generated and used for Non-Covalent Interaction (NCI) ${ }^{51}$ and Quantum Theory of Atoms In Molecules (QTAIM) ${ }^{52}$ studies.

\section{The non-covalent interaction}

The NCI is a powerful theoretical technique used for the visualization of weak non-covalent interactions in the molecules, such as steric repulsions, van der Waals interactions and the HBs. ${ }^{53}$ This approach is based on the electron density and its derivatives. The condition for the covalent and non-covalent bonding regions is that there must be very large positive

Table 3 H/D exchange rate constants and half-lives of approximately $5 \mathrm{mM}$ solution of molecules $1-4$ in the solvent $\mathrm{CDCl}_{3}$. The values were calculated using the integral area of $\mathrm{NH}$ peaks in the ${ }^{1} \mathrm{H}$ NMR spectrum of $10 \% \mathrm{CD}_{3} \mathrm{OD} / \mathrm{CDCl}_{3}$ samples

\begin{tabular}{lllr}
\hline Molecule & $\begin{array}{l}\text { Substituent } \\
(\mathrm{X})\end{array}$ & $\begin{array}{l}\text { H/D exchange rate } \\
\text { constant }(k)\left(\mathrm{min}^{-1}\right)\end{array}$ & $\begin{array}{l}\text { Half-life }\left(t_{1 / 2}\right) \\
(\mathrm{min})\end{array}$ \\
\hline $\mathbf{1}$ & $\mathrm{F}$ & $6.4 \times 10^{-3}$ & 108.28 \\
$\mathbf{2}$ & $\mathrm{Cl}$ & $7.46 \times 10^{-3}$ & 92.89 \\
$\mathbf{3}$ & OMe & $4.82 \times 10^{-3}$ & 143.77 \\
$\mathbf{4}$ & $\mathrm{H}$ & $8.19 \times 10^{-3}$ & 84.61
\end{tabular}



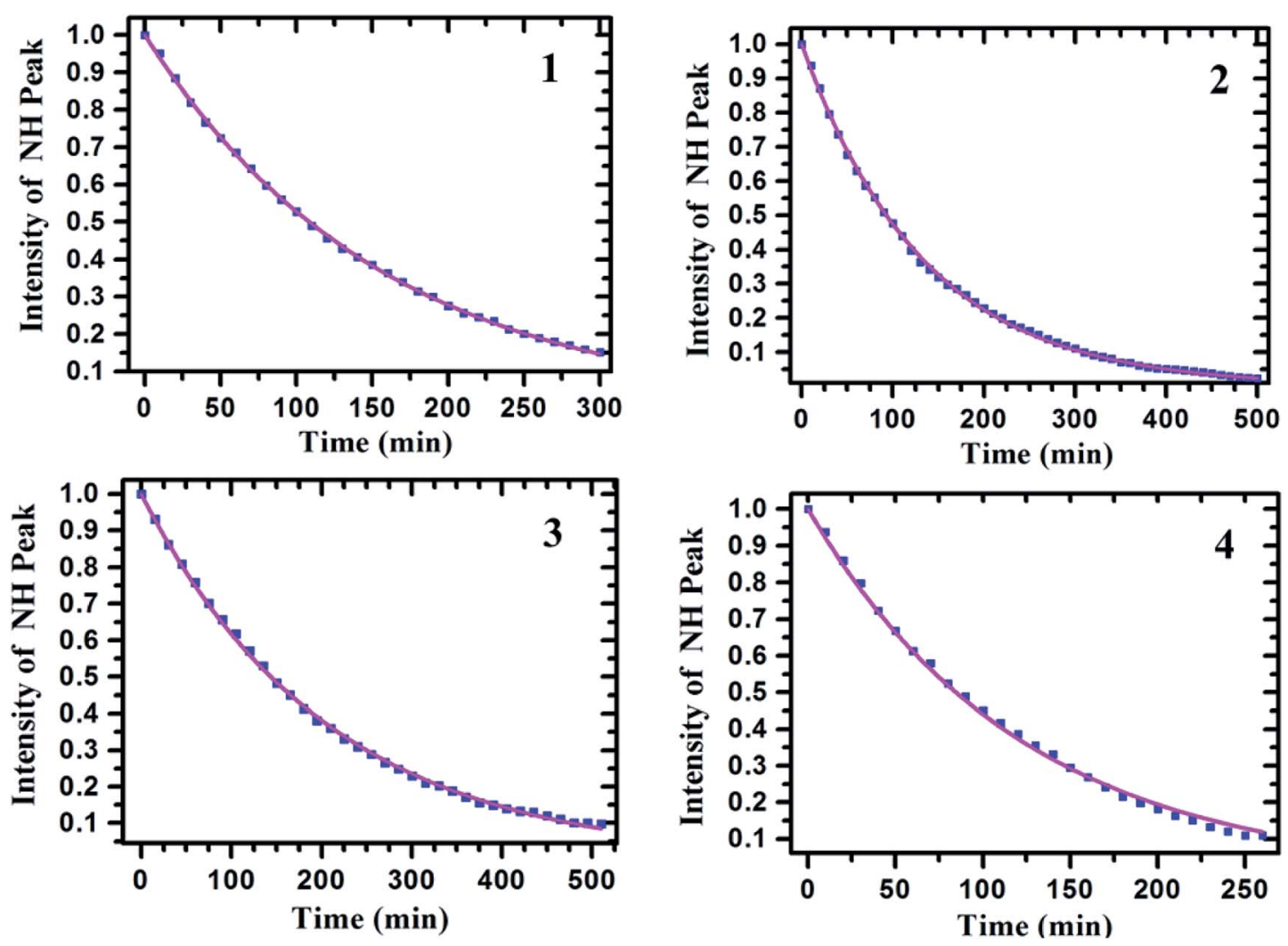

Fig. 7 The plot of integral intensity of the NH peak versus time (in min). The number in the inset refers to molecule; 1 for fluoro derivative, 2 for chloro derivative, 3 for methoxy derivative and 4 for unsubstituted molecule.

gradient of the reduced density gradient (RDG), and the RDG values have to be small, approaching to zero in the density tail, respectively. There is always a correlation between the electron density and the weak interactions in the corresponding regions.
The correlation values are negative for the HBs, positive for steric interactions, whereas for van der Waals interactions they are close to zero. RDGs are significantly important while extracting the information on the weak molecular interactions,

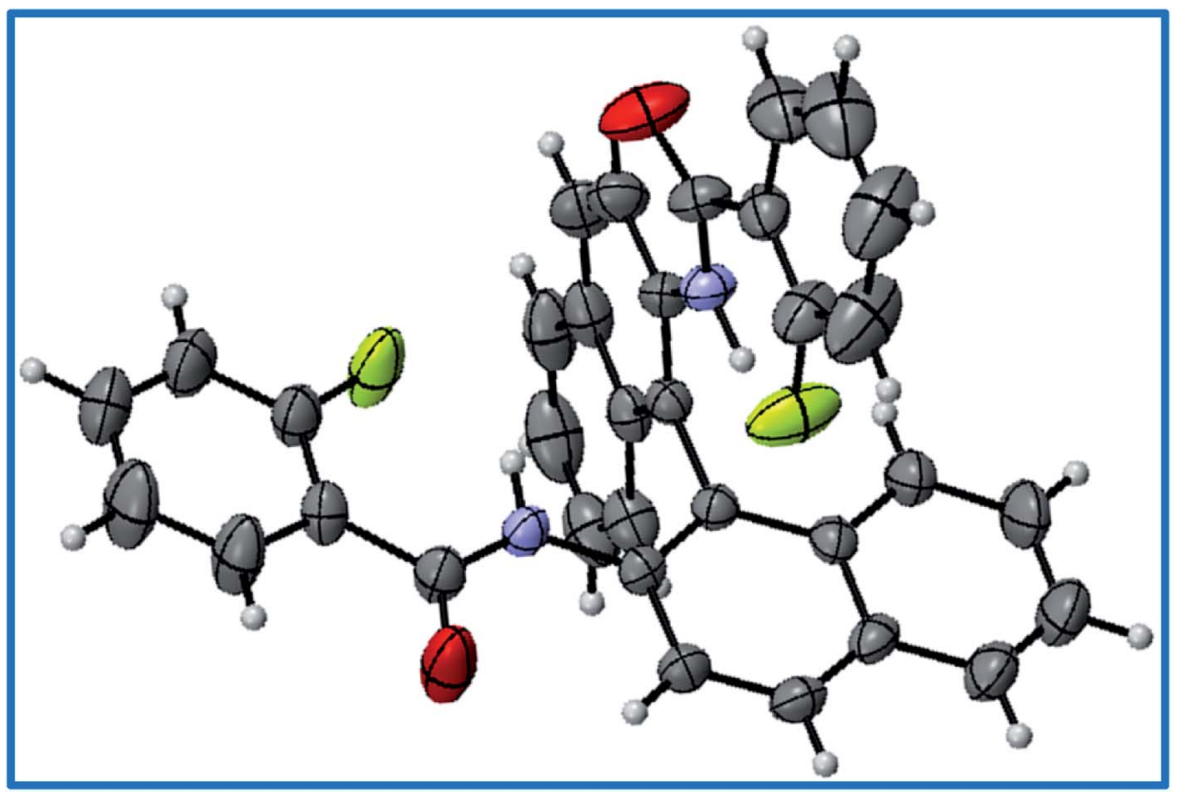

Fig. 8 The structure of molecule 1 determined from a single-crystal XRD study with ORTEP view. 
Table 4 Structural parameters obtained from the DFT calculations and single crystal XRD studies. All the bond distances are in $\AA$ and bond angles are in degree

\begin{tabular}{lcc}
\hline Parameter & DFT & XRD \\
\hline $\mathrm{NH} \cdots \mathrm{F}$ & 1.909 & 1.887 \\
$\mathrm{~N}-\mathrm{H}$ & 1.011 & 0.857 \\
$\mathrm{~N} \cdots \mathrm{F}$ & 2.732 & 1.991 \\
$<\mathrm{N}-\mathrm{H} \cdots \mathrm{F}$ & 136.27 & 138.84 \\
$<\mathrm{C}-\mathrm{F} \cdots \mathrm{H}$ & 101.32 & 99.89 \\
$\mathrm{O} \cdots \mathrm{H}$ & 2.154 & 2.226 \\
$<\mathrm{C}=\mathrm{O} \cdots \mathrm{H}$ & 121.31 & 103.01
\end{tabular}

viz. the presence of dual HB in 1,4-bis-(3-hydroxy-4-oxo- $4 H_{-}$chromen-2-yl)-benzene (bisflavonol) system is confirmed by RDGs which was observed experimentally. ${ }^{54}$ The calculated grid points are plotted for a defined real space function, with $\sin \left(\lambda_{2}(r)\right) \rho(r)$ as function 1 and the reduced density gradient (RDG) as function 2 using the Multiwfn ${ }^{55}$ program for all the molecules. Using these grid points, coloured filled isosurfaces have also been plotted by using VMD program. ${ }^{56}$ The plot of $\sin \left(\lambda_{2}(r)\right) \rho(r) v s$. RDG, and the coloured isosurfaces are given in Fig. 9(B).

\section{QTAIM calculations}

In order to study the electron density of the system, QTAIM can be used as a powerful tool. In topology analysis, critical points (CPs) are defined as the points at which the gradient norm of electron density goes to zero (except at infinity). ${ }^{57-60} \mathrm{Among}$ all four CPs, the electron density at $(3,-1)$ is known as the bond critical point (BCP). BCP arises whenever there is an attractive interaction between two atoms. Bond path (BP), which passes through the $\mathrm{BCP}$, indicates the presence of bond between atoms. The molecular models depicting the BCP and BP are reported in Fig. 10. From the information on the sign of the Laplacian of electron density $\left(\Delta^{2} \times \rho(r)\right)$ values and the electron density $(\rho(r))$, the bond type and bond strength are determined. Therefore, for all the investigated molecules, the magnitude of electron density and the Laplacian electron density at the (3, -1 ) BCPs were determined and compiled in Table 5. It is clear from the table that the Laplacian of electron density is positive, which provides the evidence for the HB type of interactions. The theoretically calculated energies of $\mathrm{HB}\left(E_{\mathrm{HB}}\right)$ show that the HBs in the present study are relatively stronger compared to the previously studied molecules. This is also reflected in the experimental data during titration study and the spectra in the solvent DMSO- $\mathrm{d}_{6}$.

\section{Experimental}

The ${ }^{1} \mathrm{H}\left\{{ }^{13} \mathrm{C}\right\}$ NMR spectra for all the compounds and the DMSO titration experiments were obtained on the $500 \mathrm{MHz}$ NMR spectrometer. All the ${ }^{1} \mathrm{H}\left\{{ }^{19} \mathrm{~F}\right\}, \mathrm{CDCl}_{3}$ titration, variable temperature studies and ${ }^{1} \mathrm{H}^{1}{ }^{19} \mathrm{~F}$-HOESY experiments were carried out on $400 \mathrm{MHz}$ NMR spectrometer. The $2 \mathrm{D}^{1} \mathrm{H}^{1}{ }^{13} \mathrm{C}$ and ${ }^{1} \mathrm{H}^{-15} \mathrm{~N}$ HSQC correlation experiments were performed on the $800 \mathrm{MHz}$ NMR spectrometer. For all the synthesized molecules, analysis of molecular mass has been carried out by using electrospray ionization mass spectrometry (ESI-HRMS). XRD data were collected on an oil coated crystal using an Oxford Xcalibur diffractometer with an Eos detector and a Mova microsource (Mo-K $\alpha$ radiation, $\lambda=0.71073 \AA$ ) equipped with an Oxford Cobra open stream non-liquid nitrogen cooling device in the $\omega$ scan mode at $100(2) \mathrm{K}$. The structure was solved by direct methods in Shelx-2014 ${ }^{61}$ and refined by full-matrix least squares methods against $\mathrm{F}^{2}$ (XD2015). ${ }^{62}$

\section{General procedure for synthesis}

The molecules were synthesized using $(R)-(+)-1,1^{\prime}$-binaphthyl$2,2^{\prime}$-diamine and benzoyl chlorides of interest with desired substitution on ortho position. The $(R)-(+)-1,1^{\prime}$-binaphthyl-2, $2^{\prime}-$ diamine and benzoyl chlorides of high purity were purchased
(A)

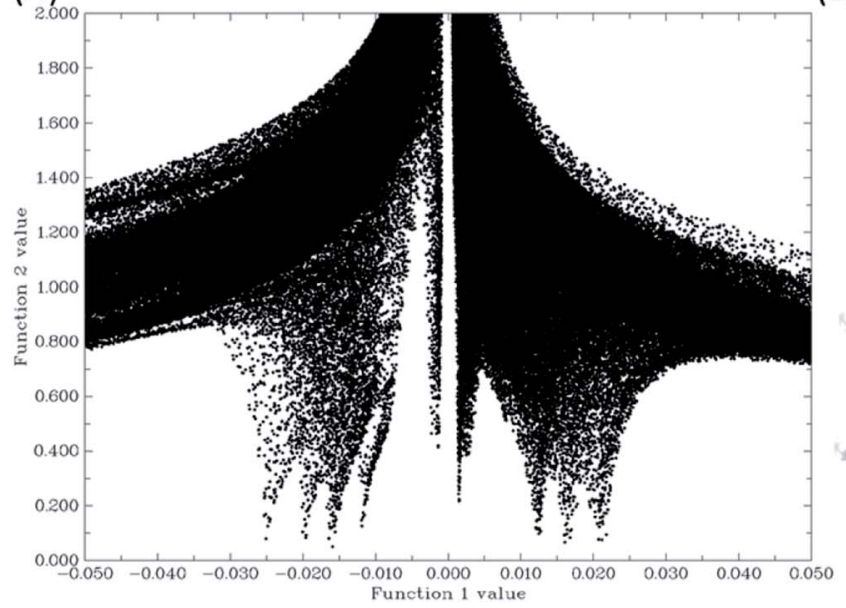

(B)

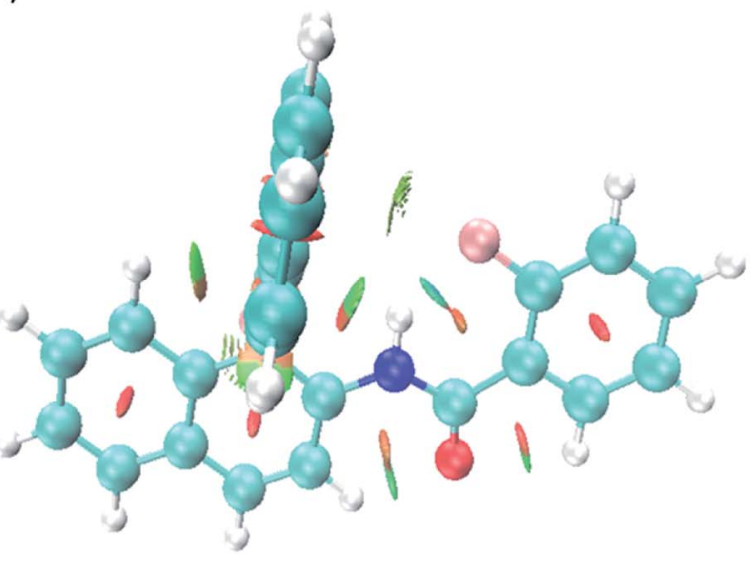

Fig. 9 (A) The plot of $\sin \left(\lambda_{2}(r)\right) \rho(r)$ as function 1 vs. the RDG as function 2, and (B) coloured isosurface plot (green colour denotes weak HB and red colour stands for steric effect) for molecule 1 . The plots for the remaining molecules, 2-4, are given in the ESI. $\dagger$ 


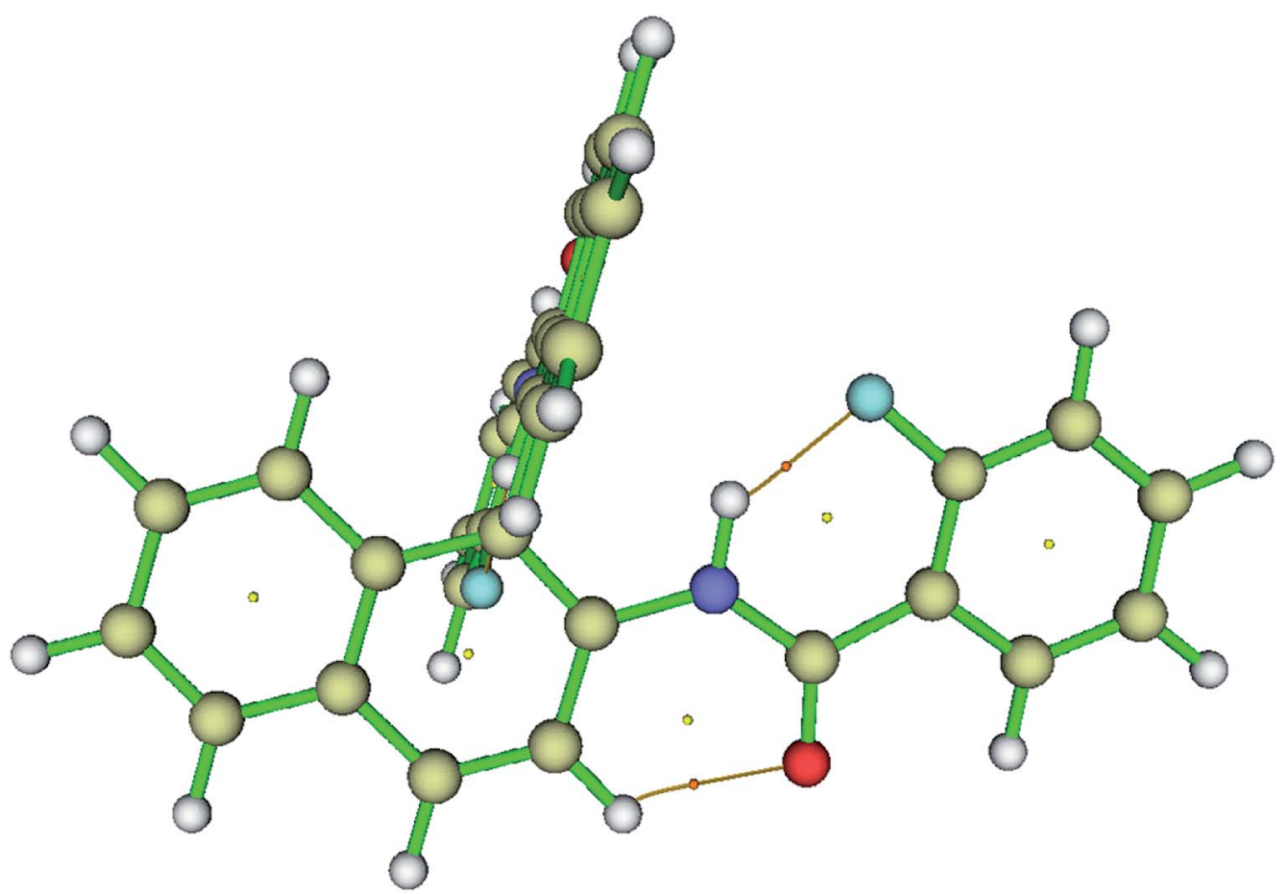

Fig. 10 The visualization of BCPs and bond paths of HB for molecule 1 plotted using Multiwfn software. Dots represent the CPs and thin bars represent the $\mathrm{HB}$ interactions.

Table 5 Electron density $(\rho(r))$ and Laplacian of electron density $\left(\Delta^{2} \rho(r)\right)$ at different BCPs of type $(3,-1)$ for $(X \cdots H N)$ HBs and the energy of particular HBs calculated on the basis of potential energy density $(V(r))$ are listed. The calculations were done using a default solvation medium of chloroform

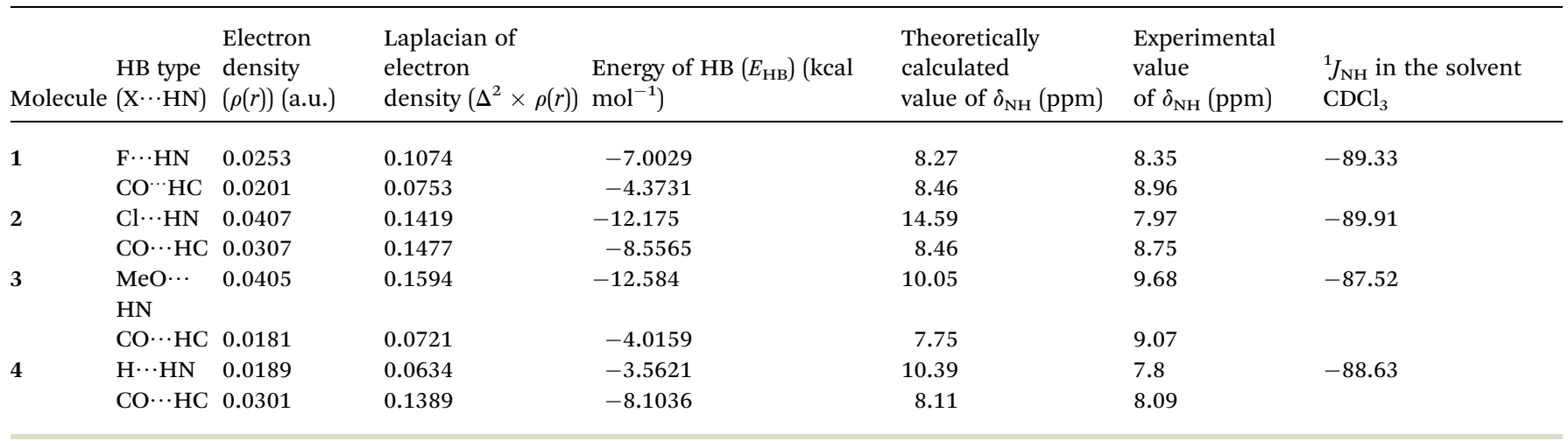

and used as received. The AR grade solvents $n$-hexane $\left(\mathrm{C}_{6} \mathrm{H}_{14}\right)$, chloroform $\left(\mathrm{CHCl}_{3}\right)$, n-pentane $\left(\mathrm{C}_{5} \mathrm{H}_{12}\right)$, dichloromethane $\left(\mathrm{CH}_{2} \mathrm{Cl}_{2}\right)$ and HPLC grade methanol $\left(\mathrm{CH}_{3} \mathrm{OH}\right)$ were used for the purification.

$200 \mathrm{mg}$ of $(R)-(+)-1,1^{\prime}$-binaphthyl-2,2'-diamine and the benzoyl chloride of interest were taken in a $1: 2.2$ molar ratio in a silica crucible and mixed using a spatula. The resulting mixture was exposed to microwave irradiation at $450 \mathrm{~W}$ for $5 \mathrm{~min}$. The reaction mixture was monitored using TLC after completion. For further purification the obtained product was passed through a column loaded with neutral alumina $\left(\mathrm{Al}_{2} \mathrm{O}_{3}\right)$ using a mixture of the solvents $n$-hexane and chloroform. The gradient of the solvent was varied from $5 \%$ to $30 \%$ chloroform with the gradual increments. The obtained product was crystallized using methanol $\left(\mathrm{CH}_{3} \mathrm{OH}\right)$ and dichloromethane $\left(\mathrm{CH}_{2} \mathrm{Cl}_{2}\right)$ in a $2: 1$ ratio.

\section{Conclusions}

The various one- and two-dimensional NMR experiments provided unambiguous evidence for the presence of intramolecular HBs in all the molecules and their relative strengths of substituted molecules follow the trend $\mathrm{OMe}>\mathrm{F}>\mathrm{Cl}>\mathrm{H}$. The studies also discarded the possibility of intermolecular $\mathrm{HB}$ and aggregation. In fluorinated derivative the two dimensional ${ }^{1} \mathrm{H}-{ }^{19} \mathrm{~F}$ HOESY experiment established the spatial proximity and provided direct and explicit evidence for the participation of organic fluorine in intramolecular HBs. Interestingly the HB 
in this molecule is very strong and is unbreakable even in high polarity solvent like DMSO, which is attributed to the structural constraint preventing the solvation of HB. The H/D exchange rates and the half-lives provided the qualitative information on the relative strengths of HBs. The NMR findings were ratified by DFT based computations. The single crystal-XRD structure provided insight into the structure and geometry of molecules and concurred with the NMR findings about the conditions for existence of intramolecular HBs. We envisage that this type of unusual behaviour of $\mathrm{HB}$ in highly polar solvent like DMSO- $\mathrm{d}_{6}$ might help in understanding the structural constraints in biomolecules, supramolecules, and foldamers.

\section{Conflicts of interest}

Authors declare no conflicts of interest.

\section{Acknowledgements}

AKP would like to thank Indian Institute of Science (IISc) for Research Fellowship. NS gratefully acknowledges the generous financial support by the Science and Engineering Research Board (SERB), New Delhi (Grant Number: CRG/2018/002006).

\section{References}

1 B. Kojić-Prodić and K. Molčanov, The nature of hydrogen bond: new insights into old theories, Acta Chim. Slov., 2008, 55, 692-708.

2 P. Schuster and P. Wolschann, Hydrogen Bonding: From Small Clusters to Biopolymers, Annu. Rev. Biochem., 1999, 960, 947-960.

3 G. R. Desiraju and T. Steiner, The Weak Hydrogen Bond, Oxford University Press, 2001.

4 P. I. Nagy, Competing intramolecular vs. intermolecular hydrogen bonds in solution, Int. J. Mol. Sci, 2014, 15, 19562-19633.

5 C. D. Sessler, M. Rahm, S. Becker, J. M. Goldberg, F. Wang and S. J. Lippard, $\mathrm{CF}_{2} \mathrm{H}, \mathrm{A}$ Hydrogen Bond Donor, J. Am. Chem. Soc., 2017, 139, 9325-9332.

6 Y. Zhang, B. Sun, D. Feng, H. Hu, M. Chu, Q. Qu, J. T. Tarrasch, S. Li, T. Sun Kobilka, B. K. Kobilka and G. Skiniotis, Cryo-EM structure of the activated GLP-1 receptor in complex with a G protein, Nature, 2017, 546, 248-253.

7 S. Chandra, D. Roy Chowdhury, M. Addicoat, T. Heine, A. Paul and R. Banerjee, Molecular Level Control of the Capacitance of Two-Dimensional Covalent Organic Frameworks: Role of Hydrogen Bonding in Energy Storage Materials, Chem. Mater., 2017, 29, 2074-2080.

8 G. A. Jeffrey, An Introduction to Hydrogen Bonding, Oxford University Press, 1997.

9 K. Piskorz, J. M. Dust, E. Buncel, O. Lebel and J. M. Nunzi, Deceleration of thermal ring closure in a glass-forming mexylaminotriazine-substituted merocyanine (MC) linked to intramolecular hydrogen bonding, New J. Chem., 2017, 41, 940-947.
10 C. Prabhakar, Promila, A. Tripathi, K. Bhanuprakash and V. Jayathirtharao, Visible absorbing croconium dyes with intramolecular hydrogen bonding: a combined experimental and computational study, J. Mol. Struct., 2017, 1146, 684-691.

11 X. Guo, Y. Tian, M. Zhang, Y. Li, R. Wen, X. Li, X. Li, Y. Xue, L. Ma, C. Xia and S. Li, Mechanistic Insight into HydrogenBond-Controlled Crystallinity and Adsorption Property of Covalent Organic Frameworks from Flexible Building Blocks, Chem. Mater., 2018, 30, 2299-2308.

12 N. Arya, S. K. Mishra and N. Suryaprakash, Intramolecular hydrogen bond directed distribution of conformational populations in the derivatives of $\mathrm{N}^{\prime}$ benzylidenebenzohydrazide, New J. Chem., 2019, 43, 13134-13142.

13 P. Shah and A. D. Westwell, The role of fluorine in medicinal chemistry, J. Enzyme Inhib. Med. Chem., 2007, 22, 527-540.

$14 \mathrm{H}$. Zhang, Y. Li and Z. Jiang, Fluorine is Flourishing in Pharmaceuticals, J. Biomol. Res. Ther., 2012, 72, 6905-6917.

15 J. D. Dunitz and R. Taylor, Organic Fluorine Hardly Ever Accepts Hydrogen Bonds, Chem.-Eur. J., 1997, 3, 89-98.

16 A. Lakshmipriya and N. Suryaprakash, Two- and ThreeCentered Hydrogen Bonds Involving Organic Fluorine Stabilize Conformations of Hydrazide Halo Derivatives: NMR, IR, QTAIM, NCI, and Theoretical Evidence, J. Phys. Chem. A, 2016, 120, 7810-7816.

17 S. K. Mishra and N. Suryaprakash, Intramolecular hydrogen bonds involving organic fluorine in the derivatives of hydrazides: an NMR investigation substantiated by DFT based theoretical calculations, Phys. Chem. Chem. Phys., 2015, 17, 15226-15235.

18 A. Lakshmipriya, S. Rama Chaudhari, A. Shahi, E. Arunan and N. Suryaprakash, Three centered hydrogen bonds of the type $\mathrm{CO} \cdots \mathrm{H}(\mathrm{N}) \cdots \mathrm{X}-\mathrm{C}$ in diphenyloxamide derivatives involving halogens and a rotating $\mathrm{CF}_{3}$ group: NMR, QTAIM, NCI and NBO studies, Phys. Chem. Chem. Phys., 2015, 17, 7528-7536.

19 S. K. Mishra and N. Suryaprakash, Intramolecular Hydrogen Bonding Involving Organic Fluorine: NMR Evidence corroborated by DFT based theoretical calculations, Molecules, 2017, 22, 423-466.

20 D. Kumari, S. Hebbar and N. Suryaprakash, Intra-molecular hydrogen bonding with organic fluorine in the solution state: deriving evidence by a two dimensional NMR experiment, Chem. Phys. Lett., 2012, 525-526, 129-133.

21 I. E. Kareev, G. S. Quiñones, I. V. Kuvychko, P. A. Khavrel, I. N. Ioffe, I. V. Goldt, S. F. Lebedkin, K. Seppelt, S. H. Strauss and O. V. Boltalina, Variable-temperature ${ }^{19} \mathrm{~F}$ NMR and theoretical study of 1,9- and 1,7- $\mathrm{C}_{60} \mathrm{~F}\left(\mathrm{CF}_{3}\right)$ and $\mathrm{C}_{\mathrm{s}}{ }^{-}$and $\mathrm{C}_{1}-\mathrm{C}_{60} \mathrm{~F}_{17}\left(\mathrm{CF}_{3}\right)$ : hindered $\mathrm{CF}_{3}$ rotation and through-space JFF coupling, J. Am. Chem. Soc., 2005, 127, 11497-11504.

22 D. Bécart, V. Diemer, A. Salaün, M. Oiarbide, Y. R. Nelli, B. Kauffmann, L. Fischer, C. Palomo and G. Guichard, Helical Oligourea Foldamers as Powerful Hydrogen Bonding Catalysts for Enantioselective C-C Bond-Forming Reactions, J. Am. Chem. Soc., 2017, 139, 12524-12532. 
23 B. K. Paul, D. Ray and N. Guchhait, Spectral deciphering of the interaction between an intramolecular hydrogen bonded ESIPT drug, 3,5-dichlorosalicylic acid, and a model transport protein, Phys. Chem. Chem. Phys., 2012, 14, 88928902.

24 S. Badigenchala, D. Ganapathy, A. Das, R. Singh and G. Sekar, Iron(II) Chloride-1,1'-Binaphthyl-2,2'-Diamine $\left(\mathrm{FeCl}_{2}-\mathrm{BINAM}\right)$ Complex Catalyzed Domino Synthesis of Bisindolylmethanes from Indoles and Primary Alcohols, Synthesis, 2014, 46, 101-109.

25 S. Kitagaki, T. Uedab and C. Mukaib, Planar chiral[2.2] paracyclophane-based bis(thiourea) catalyst: application to asymmetric Henry reaction, Chem. Commun., 2013, 49, 4030-4032.

26 D. Gary, Jaycox, Stimuli-Responsive Polymers. VII. Photomodulated Chiroptical Switches: Periodic Copolyaramides Containing Azobenzene, Phenylene, and Chiral Binaphthylene Main-Chain Linkages, J. Polym. Sci., Part A: Polym. Chem., 2003, 42, 566-577.

27 J. Zhao, H. Dong and Y. Zheng, Elaborating the excited state multiple proton transfer mechanism for $9 \mathrm{H}$ pyrido $[3,4-b]$ indole, J. Lumin., 2018, 195, 228-233.

28 C. L. Perrin, Mechanism of Hydrogen Exchange in Amides, J. Am. Chem. Soc., 1974, 96, 5628-5631.

29 S. K. Mishra and N. Suryaprakash, Study of H/D exchange rates to derive the strength of intramolecular hydrogen bonds in halo substituted organic building blocks: an NMR spectroscopic investigation, Chem. Phys. Lett., 2015, 639, 254-260.

30 P. L. Rinaldi, Heteronuclear 2D-NOE Spectroscopy, J. Am. Chem. Soc., 1983, 105, 5167-5168.

31 C. Yu and G. C. Levy, Solvent and Intramolecular Proton Dipolar Relaxation of the Three Phosphates of ATP: A Heteronuclear 2D NOE Study, J. Am. Chem. Soc., 1983, 105, 6994-6996.

32 C. Yu and G. C. Levy, Two-Dimensional Heteronuclear NOE (HOESY) Experiments: Investigation of Dipolar Interactions between Heteronuclei and Nearby Protons, J. Am. Chem. Soc., 1984, 106, 6533-6537.

33 A. J. Dingley, J. E. Masse, R. D. Peterson, M. Barfield, J. Feigon and S. Grzesiek, Internucleotide scalar couplings across hydrogen bonds in Watson-Crick and Hoogsteen base pairs of a DNA triplex, J. Am. Chem. Soc., 1999, 121, 6019-6027.

34 C. Bartolomé, P. Espinet and J. M. Martín-Alvarez, Is there any bona fide example of $\mathrm{O}-\mathrm{H} \cdots \mathrm{F}-\mathrm{C}$ bond in solution? The cases of $\mathrm{HOC}\left(\mathrm{CF}_{3}\right)_{2}\left(4-\mathrm{X}-2,6-\mathrm{C}_{6} \mathrm{H}_{2}\left(\mathrm{CF}_{3}\right)_{2}\right)\left(\mathrm{X}=\mathrm{Si}(\mathrm{i}-\mathrm{Pr})_{3}, \mathrm{CF}_{3}\right)$, Chem. Commun., 2007, 2, 4384-4386.

35 S. R. Chaudhari, S. Mogurampelly and N. Suryaprakash, Engagement of $\mathrm{CF}_{3}$ group in $\mathrm{N}-\mathrm{H} \cdots \mathrm{F}-\mathrm{C}$ hydrogen bond in the solution state: NMR spectroscopy and MD simulation studies, J. Phys. Chem. B, 2013, 117, 1123-1129.

36 M. Nakahara and C. Wakai, Monomeric and Cluster States of Water Molecules in Organic Solvent, Chem. Lett., 1992, 21, 809-812.

37 P. Dhanishta, S. K. Mishra and N. Suryaprakash, Intramolecular $\mathrm{HB}$ Interactions Evidenced in Dibenzoyl
Oxalamide Derivatives: NMR, QTAIM, and NCI Studies, $J$. Phys. Chem. A, 2018, 122, 199-208.

38 G. N. Manjunatha Reddy, M. V. Vasantha Kumar, T. N. Guru Row and N. Suryaprakash, $\mathrm{N}-\mathrm{H} \cdots \mathrm{F}$ hydrogen bonds in fluorinated benzanilides: NMR and DFT study, Phys. Chem. Chem. Phys., 2010, 12, 13232-13237.

39 A. Dunger, H. H. Limbach and K. Weisz, Geometry and strength of hydrogen bonds in complexes of 2'deoxyadenosine with 2'-deoxyuridine, J. Am. Chem. Soc., 2000, 122, 10109-10114.

40 S. H. Gellman, G. P. Dado, G. B. Liang and B. R. Adams, Conformation-Directing Effects of a Single Intramolecular Amide-Amide Hydrogen Bond: Variable-Temperature NMR and IR Studies on a Homologous Diamide Series, J. Am. Chem. Soc., 1991, 113, 1164-1173.

41 S. H. Gellman, B. R. Adams and G. P. Dado, TemperatureDependent Changes in the Folding Pattern of a Simple Triamide, J. Am. Chem. Soc., 1990, 112, 460-461.

42 F. J. Martínez-Martínez, A. Ariza-Castolo, H. Tlahuext, M. Tlahuextl and R. Contreras, ${ }^{1} \mathrm{H},{ }^{13} \mathrm{C},{ }^{15} \mathrm{~N}, 2 \mathrm{D}$ and variable temperature NMR study of the role of hydrogen bonding in the structure and conformation of oxamide derivatives, J. Chem. Soc., Perkin Trans. 2, 1993, 1481-1485.

43 S. Grzesiek, F. Cordier, V. Jaravine and M. Barfield, Insights into biomolecular hydrogen bonds from hydrogen bond scalar couplings, Prog. Nucl. Magn. Reson. Spectrosc., 2004, 45, 275-300.

44 R. A. Cormanich, M. A. Moreira, M. P. Freitas, T. C. Ramalho, C. P. A. Anconi, R. Rittner, R. H. Contreras and C. F. Tormena, ${ }^{1 \mathrm{~h}} J_{\mathrm{FH}}$ coupling in 2 -fluorophenol revisited: is intramolecular hydrogen bond responsible for this longrange coupling?, Magn. Reson. Chem., 2011, 49, 763-767.

45 S. K. Mishra and N. Suryaprakash, Organic fluorine involved intramolecular hydrogen bonds in the derivatives of imides: NMR evidence corroborated by DFT based theoretical calculations, RSC Adv., 2015, 5, 86013-86022.

46 A. V. Afonin, I. A. Ushakov, L. N. Sobenina, Z. V. Stepanova, O. V. Petrova and B. A. Trofimov, Different types of hydrogen bonds in 2-substituted pyrroles and 1-vinyl pyrroles as monitored by ${ }^{1} \mathrm{H},{ }^{13} \mathrm{C}$ and ${ }^{15} \mathrm{~N}$ NMR spectroscopy and $\mathrm{ab}$ initio calculations, Magn. Reson. Chem., 2006, 44, 59-65.

47 M. M. King, H. J. C. Yeh and G. O. Dudek, Nitrogen NMR spectroscopy: application to some substituted pyrroles, Org. Magn. Reson., 1976, 8, 208-212.

48 B. Bernet and A. Vasella, ${ }^{1} \mathrm{H}-\mathrm{NMR}$ analysis of intra- and intermolecular $\mathrm{H}$-bonds of alcohols in DMSO: chemical shift of hydroxy groups and aspects of conformational analysis of selected monosaccharides, inositols, and ginkgolides, Helv. Chim. Acta, 2000, 83, 995-1021.

49 E. Arunan, G. R. Desiraju, R. A. Klein, J. Sadlej, S. Scheiner, I. Alkorta, D. C. Clary, R. H. Crabtree, J. J. Dannenberg, P. Hobza, H. G. Kjaergaard, A. C. Legon, B. Mennucci and D. J. Nesbitt, Defining the hydrogen bond: an account (IUPAC Technical Report), Pure Appl. Chem., 2011, 83, 1619-1636.

50 M. J. Frisch, G. W. Trucks, H. B. Schlegel, G. E. Scuseria, M. A. Robb, J. R. Cheeseman, G. Scalmani, V. Barone, 
B. Mennucci, G. A. Petersson, H. Nakatsuji, M. Caricato, X. Li, H. P. Hratchian, A. F. Izmaylov, J. Bloino, G. Zheng, J. L. Sonnenberg, M. Hada, M. Ehara, K. Toyota, R. Fukuda, J. Hasegawa, M. Ishida, T. Nakajima, Y. Honda, O. Kitao, H. Nakai, T. Vreven, J. A. Montgomery Jr, J. E. Peralta, F. Ogliaro, M. J. Bearpark, J. Heyd, E. N. Brothers, K. N. Kudin, V. N. Staroverov, R. Kobayashi, J. Normand, K. Raghavachari, A. P. Rendell, J. C. Burant, S. S. Iyengar, J. Tomasi, M. Cossi, N. Rega, N. J. Millam, M. Klene, J. E. Knox, J. B. Cross, V. Bakken, C. Adamo, J. Jaramillo, R. Gomperts, R. E. Stratmann, O. Yazyev, A. J. Austin, R. Cammi, C. Pomelli, J. W. Ochterski, R. L. Martin, K. Morokuma, V. G. Zakrzewski, G. A. Voth, P. Salvador, J. J. Dannenberg, S. Dapprich, A. D. Daniels, Ö. Farkas, J. B. Foresman, J. V. Ortiz, J. Cioslowski and D. J. Fox, Gaussian, Inc., Wallingford, CT, USA, 2009.

51 J. Contreras-García, W. Yang and E. R. Johnson, Analysis of hydrogen-bond interaction potentials from the electron density: integration of noncovalent interaction regions, $J$. Phys. Chem. A, 2011, 115, 12983-12990.

52 R. F. W. Bader, Atoms in Molecules: A Quantum Theory, Oxford University Press, Oxford, 1994.

53 E. R. Johnson, S. Keinan, P. Mori-sánchez, J. Contrerasgarcía, J. Aron and W. Yang, Revealing Noncovalent Interactions, J. Am. Chem. Soc., 2011, 132, 6498-6506.
54 J. Zhao, H. Dong, H. Yang and Y. Zheng, Exploring and elaborating the novel excited state dynamical behavior of a bisflavonol system, Org. Chem. Front., 2018, 5, 2710-2718.

55 T. Lu and F. Chen, Multiwfn: a multifunctional wavefunction analyzer, J. Comput. Chem., 2012, 33, 580-592.

56 W. Humphrey, A. Dalke and K. Schulten, VMD: Visual Molecular Dynamics, J. Mol. Graphics, 1996, 14, 33-38.

57 R. F. W. Bader, S. G. Anderson and A. J. Duke, Quantum Topology of Molecular Charge Distributions, J. Am. Chem. Soc., 1979, 101, 1389-1395.

58 R. F. W. Bader and H. Essén, The characterization of atomic interactions, J. Chem. Phys., 1984, 80, 1943-1960.

59 R. F. W. Bader, T. T. Nguyen-Dang and Y. Tal, A topological theory of molecular structure, Rep. Prog. Phys., 1981, 44, 893948.

60 G. R. Runtz, R. F. W. Bader and R. R. Messer, Definition of bond paths and bond directions in terms of the molecular charge distribution, Can. J. Chem., 1977, 55, 3040-3045.

61 G. M. Sheldrick, Crystal structure refinement with SHELXL, Acta Crystallogr., Sect. C: Struct. Chem., 2015, 71, 3-8.

62 M. Refinement, Manual Version 2015 Program Version 6.03, February 2015. 